\title{
FITOTECNIA
}

\section{EFICÁCIA DO HERBICIDA GLIFOSATO-POTÁSSICO SUBMETIDO À CHUVA SIMULADA APÓS A APLICAÇÃO(1)}

\author{
GUSTAVO MARTINI ${ }^{(2)}$; AIMAR FRANCISCO FERRARI PEDRINHO JUNIOR ${ }^{(2)}$; \\ JULIO CEZAR DURIGAN ${ }^{(3)}$
}

\begin{abstract}
RESUMO
Apesar de possuir boa ação herbicida, alguns fatores afetam a eficácia do glifosato e, nesse contexto, realizaram-se estudos buscando formulações mais eficazes. O experimento foi instalado em área do Campus da FCAV-UNESP, Jaboticabal (SP). Testou-se a formulação potássica de glifosato comparada com solução aquosa e grânulos dispersíveis em água à mesma dosagem $(0,36 \mathrm{~kg}$.ha-1 e.a) em cinco intervalos (1, 2, 4, 6 e > 48 horas) sem chuva após a aplicação, comparados com uma testemunha sem uso de herbicidas. Foram aplicados em pós-emergência sobre Brachiaria plantaginea, B. decumbens e Digitaria horizontalis. A aplicação foi feita com pulverizador costal a $\mathrm{CO}_{2}$ à pressão de $2,5 \mathrm{~kg} \cdot \mathrm{cm}^{-2}$, munido de barra com seis bicos DG 110.02 e consumo de calda equivalente a 200 L.ha $^{-1}$. Realizaram-se cinco avaliações de porcentagem de controle em relação à testemunha infestada, atribuídas visualmente, até 42 dias após aplicação. Notou-se que o controle da formulação potássica sobre as espécies avaliadas foi mais precoce, necessitando apenas quatro horas após sua aplicação para se igualar ao intervalo superior a 48 horas sem chuva. As demais necessitaram de, no mínimo, seis horas de intervalo.
\end{abstract}

Palavras-chave: pós-emergência, velocidade de absorção, formulações.

\section{ABSTRACT \\ EFFECTS OF RAINFALL ON EFFICACY THE POTASSIUM GLYPHOSATE IN WEEDS}

In spite of possessing good herbicidal action, some factors affect the effectiveness of the glyphosate and, in that context, studies were accomplished looking for more effective formulations. The experiment was installed in area of FCAV-UNESP Campus, in Jaboticabal, São Paulo State. The potassium glyphosate formulation was compared to CS and WG formulations, at the same rate $\left(0.36 \mathrm{~kg}\right.$.ha ${ }^{-1}$ a.e), in five intervals $(1,2,46$ and 48 hours) without rain after the application, compared to a control without herbicides. They were applied in post emergence on Brachiaria plantaginea, B. decumbens and Digitaria horizontalis. The herbicides were applied with costal sprayer, at a constant pressure $\left(35 \mathrm{lbf} / \mathrm{pol}^{2}\right)$, with four nozzles DG 11002. The equivalent spray volume was $200 \mathrm{~L} \mathrm{ha}^{-1}$. The weeds control by potassium glyphosate was the earliest, it needs only four hours without rainfall after application to have a control equivalent to that treatement without rain for 48 hours after the application. The other formulations need at least six hours of interval.

Key words: post emergence, absorption, formulations.

( $\left.{ }^{1}\right)$ Recebido para publicação em 11 de junho de 2002 e aceito em 3 de janeiro de 2003.

(2) Pós-graduando em Agronomia na FCAV/UNESP. Via de acesso Paulo D. Castellane, 14870-000 Jaboticabal (SP).

$\left(^{2}\right)$ Departamento de Fitossanidade, FCAV/UNESP - Jaboticabal (SP). E-mail: jdurigan@fcav.unesp.br 


\section{INTRODUÇÃO}

O glifosato é um excelente herbicida para o controle de plantas daninhas, quando aplicado em pós-emergência. Devido a sua grande eficácia e seu baixo preço, tornou-se um dos herbicidas mais utilizados. Encontra-se formulado como concentrado solúvel (CS), a 360 ou 480 g.L.- e.a, solução aquosa concentrada (SAC) a 360 g. $\mathrm{L}^{-1}$ e.a., grânulos dispersíveis em água (GRDA) a 720 g.L - $^{-1}$ e.a., Transorb, a 480 g.L. $\mathrm{L}^{-1}$ e.a, e também pode apresentarse associado a outros herbicidas, como o diuron, o 2,4-D amina e a simazina (RodRIGUEs e AlmEIDA, 1998).

A eficácia de um herbicida aplicado às folhas das plantas daninhas está estreitamente relacionada à magnitude do processo de absorção, tanto para aqueles que possuam ação local (tópica) quanto para os que se translocam (sistêmicos) e exercem sua ação fitotóxica em sítios específicos distantes do ponto de absorção (Camargo e Silva, 1975 citados por DuRIgaN, 1993).

DeUber (1982) cita estudos feitos com vários herbicidas, mostrando que a absorção é limitada pela quantidade do produto que atravessa a cutícula da folha sendo influenciada pelas condições ambientais onde a planta daninha está se desenvolvendo. A umidade do solo, a temperatura e a umidade relativa do ar interferem no comportamento dos herbicidas nas plantas (Devine et al., 1983). A estrutura molecular, a utilização de adjuvantes e as condições climáticas influenciam, de forma significativa, nos processos de absorção e translocação do glifosato (KRUSE et al., 2000).

O glifosato atravessa a cutícula com velocidade moderada, necessitando, em média, de seis horas sem chuvas após a aplicação para haver controle adequado de plantas sensíveis. É possível que a absorção relativamente lenta de glifosato ocorra devido ao valor muito baixo do seu coeficiente de partição octanol por água (-4) em comparação a outros herbicidas, o que lhe confere baixa lipofilicidade e alta solubilidade em água. Assim, novas formulações apresentam surfatantes que conferem maior apolaridade à solução aplicada, facilitando a absorção foliar dos inibidores de EPSPs (BOERBOON e WYSE, 1988; MAC IsAaC et al.,1991). WALDECKER e WYSE (1985) demonstraram que a maior barreira para a absorção do glifosato em plantas de Asclepias syriaca é a superfície da folha, principalmente se submetidas a estresse hídrico. TUCKER et al. (1994) demonstraram que o imazapyr é mais absorvido e translocado em Alternanthera philoxeroides do que o glifosato, devido à maior afinidade com a cutícula da planta, podendo-se inferir que o imazapyr é mais lipofílico do que o glifosato.
FEnG et al. (2000) estudaram glifosato marcado com ${ }^{14} \mathrm{C}$ em plantas de Abutilon theophrasti. A retenção foliar, a absorção e a translocação foram bastante influenciadas pelas diferentes formulações testadas. Segundo os autores, a formulação sal glifosato-trimesium (412 g.L $\mathrm{L}^{-1}$ e.a) fica retida por mais tempo nas folhas da planta do que as que contém o sal glifosato-isopropilamino (360 g. $\mathrm{L}^{-1}$ e.a).

A quantidade de produto que penetrou nas folhas e a translocação na planta, tanto para período de quatro horas como para os de 24 e 120 horas após a aplicação, foram maiores para as formulações que continham o sal glifosato-isopropilamino.

Precipitações pluviais após a aplicação de herbicidas, em pós-emergência, podem comprometer o desempenho no controle de plantas daninhas (Behrens e ElakKad, 1983). Dessa forma, o intervalo de tempo entre a aplicação e a ocorrência de chuvas, bem como a quantidade e a intensidade das mesmas, as formulações e as concentrações dos herbicidas utilizados, influenciam na eficácia do controle das plantas daninhas (Hammerton, 1967; Anderson e ARNOLD, 1984).

MAROCHI et al. (1995) constataram que o período entre a aplicação e a chuva afeta significativamente a eficácia dos herbicidas glifosato e sulfosato. Intervalos de seis e oito horas sem chuva proporcionam melhores resultados, não diferindo estatisticamente entre si.

Também constataram que o sulfosato foi $20 \%$ superior ao glifosato para os intervalos de zero, duas e quatro horas sem chuva após a aplicação. Em outro estudo da influência da chuva simulada sobre diferentes formulações de nicosulfuron, constatou-se maior eficácia do herbicida, para o controle de Brachiaria plantaginea, quando os intervalos sem chuva foram aumentados de 30 minutos após a aplicação, para plantas mantidas em solo com elevada umidade. Em solo com menor umidade, a eficácia foi muito menor, mesmo quando a chuva ocorreu 120 minutos após a aplicação (BASTIANI et al., 2000).

Bovey et at. (1990), estudando o efeito da chuva simulada, com diferentes herbicidas, no controle de Acacia farnesiana e Prosopis glandulosa, constataram que as atividades foliares do glifosato, dicamba, picloran, clopyralid e triclopyr amine foram diminuídas quando submetidos à chuva após período de 240 minutos da aplicação, em casa de vegetação. BACHIEGA et al. (2000) testaram a influência de períodos livres de chuva após a aplicação $(1,2,4$ e $8 \mathrm{~h})$ para diferentes dosagens de glifosato (180 e 360 g.L $\mathrm{L}^{-1}$ e.a) e sulfosato (180 e 360 g.L L $^{-1}$ e.a), visando ao controle de Brachiaria decumbens. 
Observaram que a ação de ambos foram significativamente afetadas, em todas as dosagens, quando ocorreu chuva uma hora após a da aplicação.

No intervalo de duas e quatro horas, o sulfosato proporcionou níveis de controle mais elevados para a menor dosagem testada, não se constatando, porém, diferenças significativas entre eles na maior dosagem testada. McIntyre e BARbe (1995), comparando diferentes horários de aplicação da chuva simulada sobre a eficácia do glifosato a $1 \mathrm{~kg} \cdot \mathrm{ha}^{-1}$, para o controle de Cyperus rotundus, constataram que o menor intervalo entre a aplicação e a precipitação afetou substancialmente a ação do herbicida.

Apesar de o glifosato ser, aparentemente, um herbicida de fácil manuseio, sua aplicação requer alguns cuidados para que se obtenha resultados satisfatórios no controle das plantas daninhas. Fazse necessário maior volume de pesquisas para melhor compreensão da interação entre características relacionadas ao ambiente, às plantas, aos herbicidas e às técnicas de aplicação, influenciando aos resultados de controle. Por todos esses motivos, objetivou-se avaliar a eficácia do sal potássico de glifosato submetida a diferentes intervalos de chuva simulada após sua aplicação, comparada às formulações CS e WG.

\section{MATERIAL E MÉTODOS}

O experimento foi instalado e desenvolvido em área irrigada da Faculdade de Ciências Agrárias e Veterinárias - UNESP. O clima da região caracteriza-se por possuir temperatura média no mês mais quente (janeiro ou dezembro) de $24,3{ }^{\circ} \mathrm{C}$ e do mês mais frio (junho) de $18,6^{\circ} \mathrm{C}$. A precipitação média anual é de $1.388,0 \mathrm{~mm}$ e as temperaturas médias anuais máximas e mínimas são de $29,4{ }^{\circ} \mathrm{C}$ e $17,0{ }^{\circ} \mathrm{C}$ respectivamente. $\mathrm{O}$ solo é classificado, segundo CENTURION (1998), como Latossolo Vermelho-Escuro, eutrófico, horizonte A moderado, textura muito argilosa e relevo suave ondulado.

Foram testadas as formulações de glifosato concentrado solúvel (Roundup CS), grânulos dispersíveis em água (Roundup WG) e glifosato-potássico (ZAPP Qi). Para avaliar a interferência do período livre de chuvas na eficácia do glifosato-potássico utilizou-se, como padrão as formulações CS e WG na dose de 0,36 kg.ha- ${ }^{-1}$.

Os herbicidas foram submetidos a cinco intervalos (1, 2, 4, 6 e >48 horas) livre de chuva simulada após a aplicação, além da testemunha sem aplicação de herbicidas. Utilizou-se o delineamento experimental de blocos casualizados, com dezesseis tratamentos em quatro repetições.
As parcelas mediam $3 \mathrm{~m}$ de largura e $5 \mathrm{~m}$ de comprimento, perfazendo área de $15 \mathrm{~m}^{2}$. A análise estatística foi realizada com transformação dos dados de porcentagem de controle para arco sen $\mathrm{v} \%$, segundo o esquema fatorial $3 \times 5$, respectivamente para os seguintes fatores: formulações do glifosato (F), intervalo de tempo entre a aplicação dos herbicidas e a chuva simulada $(\mathrm{H})$. Foi mantido um tratamento testemunha adicional, sem aplicação de herbicida.

As parcelas foram infestadas pela semeadura a lanço das plantas daninhas capim-marmelada (Brachiaria plantaginea) e capim-braquiária (Brachiaria decumbens). Havia grande quantidade de sementes de capim-colchão (Digitaria horizontalis) remanescentes do cultivo anterior ao experimento.

Por ocasião da instalação do experimento, as seguintes plantas daninhas com suas respectivas médias de altura e porcentagens de infestação, que ocorreram na área experimental foram: capim-marmelada com 30 a $35 \mathrm{~cm}$ (sem inflorescência) e 55\%; capim-braquiária com $25 \mathrm{~cm}$ (sem inflorescência) e 15\%; capim-colchão, com 30 a $35 \mathrm{~cm}$ (com inflorescência) e $20 \%$.

Os herbicidas foram aplicados em pós-emergência das plantas daninhas com um pulverizador costal manual, à pressão constante (mantida pelo $\mathrm{CO}_{2}$ comprimido) de $2,5 \mathrm{kgf} / \mathrm{cm}^{2}$, munido de barra com seis bicos de jato plano ("leque") DG 110.02 e consumo de calda equivalente a 200 L.ha $^{-1}$.

As aplicações dos herbicidas foram realizadas em horários diferentes no decorrer do dia, de modo a se conseguir os diferentes intervalos sem chuva simulada artificial sobre os tratamentos. Os ventos no decorrer da aplicação dos tratamentos apresentavam-se fracos e intermitentes ou ausentes, sem promover prejuízos para as aplicações.

Os demais dados climáticos, específicos para cada horário da aplicação, são apresentados no quadro 1. A chuva foi simulada por meio de irrigação por aspersão, correspondendo a uma precipitação pluvial média de 24,2 mm, em 90 minutos.

Realizaram-se as avaliações de controle geral das principais espécies presentes na área, visualmente, aos 7, 14, 21, 28 e 42 dias após a aplicação (DAA). As porcentagens de controle foram atribuídas comparando-se as parcelas tratadas com as das testemunhas sem herbicidas e com as que tiveram intervalo superior a 48 horas, do respectivo bloco.

Aos 30 dias após a instalação do experimento pode-se ver o estágio de desenvolvimento das plantas daninhas presentes na área, com predominância de capim-marmelada e capim-braquiária. 
Quadro 1. Condições climáticas durante o horário em que foram realizadas as aplicações dos herbicidas. Jaboticabal (SP), $1999 / 2000$

\begin{tabular}{|c|c|c|c|c|c|}
\hline $\begin{array}{l}\text { Períodos sem } \\
\text { chuva artificial } \\
\text { simulada (horas) }\end{array}$ & Horário da aplicação & $\begin{array}{c}\text { Temperatura } \\
\text { do ar }\end{array}$ & $\begin{array}{c}\text { Temperatura } \\
\text { do solo a } 5 \mathrm{~cm} \\
\text { de profundidade }\end{array}$ & U.R.ar ${ }^{(1)}$ & Nebulosidade \\
\hline & & (2) & 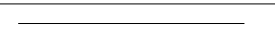 & 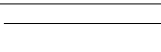 & $\%$ \\
\hline 1 & $13: 30$ às $13: 40$ & 31,5 & 26,9 & 70 & 60 \\
\hline 2 & $12: 15$ às $12: 30$ & 30,0 & 25,4 & 72 & 70 \\
\hline 4 & $10: 15$ às $10: 30$ & 29,5 & 23,5 & 72 & 75 \\
\hline 6 & $7: 55$ às $8: 15$ & 24,0 & 22,5 & 91 & 90 \\
\hline$>48$ & 7:55 às 8:15 & 24,0 & 22,5 & 91 & 90 \\
\hline
\end{tabular}

(1) URar - umidade relativa do ar.

\section{RESULTADOS E DISCUSSÃO}

$\mathrm{O}$ teste $\mathrm{F}$ aplicado às médias das porcentagens de controle atribuídas nas avaliações visuais mostrou haver significância na interação entre formulações e períodos sem chuva aos 14, 28 e 42 dias após a aplicação dos herbicidas (Quadro 2). Nessas épocas, o glifosato potássico apresentou controle estatisticamente superior aos demais e a chuva afetou de forma negativa o controle das plantas daninhas pelas formulações estudadas. Houve relação direta entre a diminuição do período sem chuva e as porcentagens de controle obtidas.

Os melhores resultados sempre foram obtidos quando o período sem chuva foi superior a 48 horas. Como o glifosato possui características hidrofílicas em sua molécula, sua absorção é lenta devido à presença de uma cutícula que recobre a superfície dos vegetais.

Essa cutícula possui propriedades apolares e torna-se uma barreira à penetração do herbicida, necessitando, dessa forma, maiores períodos a fim de que quantidades letais possam penetrar e se translocar pela planta. Segundo MAROCHI et al. (1995), o sulfosato superou o nível de controle proporcionado pelo glifosato em cerca de $20 \%$, com períodos de 0 , 2 e 4 horas sem chuva.

Aos 14 DAA (Quadro 3), a formulação de glifosato potássico apresentou melhor desempenho que as outras, com intervalo de apenas uma hora de chuva logo após a aplicação. À medida que aumentou o intervalo para duas horas, seus resultados igualaram-se aos proporcionados pela formulação CS. Com seis horas ou mais sem chuva artificial, as três formulações foram iguais. Todas as formulações tiveram a ação reduzida pela chuva, mesmo seis horas após a aplicação, variando entre $67,5 \%$ e $62,5 \%$ de controle, estabilizando em $83,7 \%$ com aplicação de chuvas 48 horas após.

Aos 28 DAA (Quadro 4), o controle atingiu patamares superiores a $90,0 \%$, para o período sem chuva superior a 48 horas, garantindo bom nível de controle das plantas daninhas avaliadas. No tratamento sem chuva por 48 horas, depois de aplicados os herbicidas, as porcentagens de controle eram de 90,7\% (glifosato CS), 95,2\% (glifosato WG) e 92,5\% (glifosato-potássico), enquanto para aquele que recebeu chuva após 6 horas, os percentuais eram 73,7\%; $80,0 \%$ e $77,5 \%$ respectivamente.

Somente para a formulação WG houve diferença significativa entre os percentuais obtidos com 6 e 4 horas de intervalo sem chuva, caracterizando maior facilidade de lavagem antes da absorção. Já aos 42 DAA (Quadro 5) algumas reduções atribuídas visualmente nas porcentagens-controle foram notadas, pelo fato de o aparecimento de plantas emergidas do novo fluxo de germinação na área, pois tais herbicidas não possuem efeito residual no solo capaz de inibir esse processo.

Resultados não concordantes foram obtidos por MAROCHI et al. (1995), mostrando que os períodos de 6 e 8 horas sem chuva após a aplicação foram suficientes para que não ocorressem prejuízos na ação deste herbicida, com total controle das plantas daninhas presentes na área experimental. BOvey et al. (1990), porém, verificaram que a ocorrência de chuva 4 horas após a aplicação reduziu a ação dos herbicidas glifosato, dicamba, picloram, clopyralid e triclopyr amine no controle de Acacia farnesiana e Prosopis glandulosa. Feng et al. (2000) também observaram que há diferenças de absorção e translocação entre as formulações de glifosato. 
Quadro 2. Resultados do teste $\mathrm{F}$ aplicado às porcentagens de controle geral das plantas daninhas com diferentes períodos de chuva simulada após a aplicação das formulações do herbicida glifosato. Jaboticabal (SP), 2000

\begin{tabular}{|c|c|c|c|c|c|c|}
\hline \multirow{2}{*}{ Fatores } & & \multicolumn{5}{|c|}{ Dias após aplicação } \\
\hline & & 7 & 14 & 21 & 28 & 42 \\
\hline Formulações (F) & & $22,86^{* *}$ & $17,75^{* *}$ & $17,76^{* *}$ & $22,86^{* *}$ & $25,43^{* *}$ \\
\hline Período sem chuva (P) & & $133,22^{* *}$ & $174,74^{* *}$ & $74,80^{* *}$ & $70,85^{* *}$ & $98,51^{* *}$ \\
\hline $\mathrm{F} \times \mathrm{P}$ & & $1,74^{\mathrm{NS}}$ & $2,86^{*}$ & $2,08^{\mathrm{NS}}$ & $5,67^{* *}$ & $7,34^{* *}$ \\
\hline \multirow[t]{2}{*}{ CV $(\%)$} & & 10,0 & 7,5 & 7,6 & 8,0 & 8,4 \\
\hline & Glifosato potássico ${ }^{(1)}$ & (a) $41,7 \mathrm{~A}(44,5)^{(\mathrm{b})}$ & & $56,2 \mathrm{~A}(68,0)$ & & \\
\hline \multirow[t]{2}{*}{ Formulações } & Glifosato SAqC ${ }^{(2)}$ & 35,9 В $(35,5)$ & & 51,3 B $(60,2)$ & & \\
\hline & Glifosato $\operatorname{GrDA}^{(3)}$ & 34,0 B $(33,0)$ & & 48,9 B $(56,2)$ & & \\
\hline \multirow[t]{3}{*}{$\mathrm{dms}$ a $5 \%$} & & 2,86 & & 3,03 & & \\
\hline & 1 & (a) $23,3 \mathrm{E}(16,5)^{(\mathrm{b})}$ & & $41,3 \mathrm{D}(43,7)$ & & \\
\hline & 2 & $28,5 \mathrm{D}(23,3)$ & & 46,0 C $(51,7)$ & & \\
\hline \multirow[t]{3}{*}{ Período sem chuva $(\mathrm{H})$} & 4 & $36,8 \mathrm{C}(36,2)$ & & 52,2 B $(62,1)$ & & \\
\hline & 6 & 42,0 B $(45,0)$ & & 54,0 B $(65,4)$ & & \\
\hline & $>48$ & 55,3 A $(67,5)$ & & 67,3 A $(84,6)$ & & \\
\hline
\end{tabular}

dms a $5 \%$

4,34

4,59

$\left({ }^{a}\right)$ Dados transformados em arc sen $\sqrt{ } \%$. (b) Dados originais. $\left({ }^{1}\right)$ ZAPP Qi. $\left({ }^{2}\right)$ ROUNDUP CS. $\left({ }^{3}\right)$ ROUNDUP WG.

Quadro 3. Comparação das médias de porcentagem de controle geral das plantas daninhas aos 14 dias após a aplicação das formulações do herbicida glifosato, com diferentes períodos de chuva simulada após a aplicação. Jaboticabal (SP), 2000

\begin{tabular}{|c|c|c|c|c|c|}
\hline \multirow{2}{*}{ Formulações } & \multicolumn{5}{|c|}{ Períodos sem chuva (h) } \\
\hline & 1 & 2 & 4 & 6 & $>48$ \\
\hline glifosato potássico $\left({ }^{1}\right)$ & a $39,2^{*} \mathrm{C}(40,0)^{* *}$ & a $42,1 \mathrm{C}(45,0)$ & a $49,3 \mathrm{~B}(52,5)$ & a $55,2 \mathrm{~B}(67,5)$ & a $66,4 \mathrm{~A}(83,7)$ \\
\hline glifosato SAqC $\left({ }^{2}\right)$ & b $31,5 \mathrm{D}(27,5)$ & ab $39,1 \mathrm{C}(40,0)$ & $\mathrm{ab} 46,5 \mathrm{~B}(52,5)$ & a $52,3 \mathrm{~B}(62,5)$ & a $66,4 \mathrm{~A}(83,7)$ \\
\hline glifosato $\operatorname{GrDA}\left({ }^{3}\right)$ & c $23,5 \mathrm{E}(16,2)$ & b 34,7 D $(32,5)$ & b $42,11 \mathrm{C}(45,0)$ & a 52,2 B $(62,5)$ & a $66,4 \mathrm{~A}(83,7)$ \\
\hline
\end{tabular}

$\mathrm{dms}$ para períodos sem chuva dentro de cada formulação $=7,12$

dms para formulações dentro de cada período sem chuva $=6,07$

*Dados transformados em arc sen $\sqrt{ } \%$. ${ }^{*} \overline{\mathrm{O}}$ s dados apresentados entre parênteses são os originais.

( $\left.{ }^{1}\right)$ ZAPP Qi.

$\left(^{2}\right)$ ROUNDUP CS.

$\left({ }^{3}\right)$ ROUNDUP WG.

Letras minúsculas do lado esquerdo e no sentido da colunas, comparam as formulações dentro de cada período; letras maiúsculas do lado direito e no sentido das linhas, comparam os períodos dentro de cada formulação. 
Quadro 4. Comparação das médias de porcentagem de controle geral das plantas daninhas aos 28 dias após a aplicação das formulações do herbicida glifosato, com diferentes períodos de chuva simulada após a aplicação. Jaboticabal (SP), 2000

\begin{tabular}{|c|c|c|c|c|c|}
\hline \multirow{2}{*}{ Formulações } & \multicolumn{5}{|c|}{ Períodos sem chuva (h) } \\
\hline & 1 & 2 & 4 & 6 & $>48$ \\
\hline glifosato potássico $\left({ }^{1}\right)$ & a $53,9 * \mathrm{C}(65,0)^{* *}$ & a $59,7 \mathrm{BC}(73,7)$ & a $67,8 \mathrm{AB}(85,0)$ & a $63,5 \mathrm{BC}(80,0)$ & a $74,3 \mathrm{~A}(92,5)$ \\
\hline glifosato SAqC $\left(^{2}\right)$ & a $46,4 \mathrm{C}(52,5)$ & a $55,4 \mathrm{BC}(67,5)$ & a $62,94 \mathrm{~B}(78,7)$ & a $61,4 \mathrm{~B}(73,7)$ & a $73,5 \mathrm{~A}(90,7)$ \\
\hline glifosato GrDA $\left({ }^{3}\right)$ & b $32,8 \mathrm{D}(30,0)$ & b $43,5 \mathrm{C}(47,5)$ & b 52,2 C $(62,5)$ & a 62,3 B $(77,5)$ & a 78,1 A $(95,2)$ \\
\hline
\end{tabular}

dms para períodos sem chuva dentro de cada formulação $=9,56$

dms para formulações dentro de cada período sem chuva $=8,14$

* Dados transformados em arc sen $\sqrt{\%} . *$ Os dados apresentados entre parênteses são os originais.

$\left({ }^{1}\right)$ ZAPP Qi.

$\left({ }^{2}\right)$ ROUNDUP CS.

$\left({ }^{3}\right)$ ROUNDUP WG.

Letras minúsculas do lado esquerdo e no sentido da colunas, comparam as formulações dentro de cada período; letras maiúsculas do lado direito e no sentido das linhas, comparam os períodos dentro de cada formulação.

Quadro 5. Comparação das médias de porcentagem de controle geral das plantas daninhas aos 42 dias após a aplicação das formulações do herbicida glifosato, com diferentes períodos de chuva simulada após a aplicação. Jaboticabal (SP), 2000

\begin{tabular}{|c|c|c|c|c|c|}
\hline \multirow{2}{*}{ Formulações } & \multicolumn{5}{|c|}{ Períodos sem chuva (h) } \\
\hline & 1 & 2 & 4 & 6 & $>48$ \\
\hline glifosato potássico $\left({ }^{1}\right)$ & a $47,9^{*} \mathrm{~B}(55,0)^{* *}$ & a $52,7 \mathrm{~B}(62,5)$ & a $64,3 \mathrm{~A}(80,0)$ & a $63,5 \mathrm{~A}(80,0)$ & a $71,2 \mathrm{~A}(88,7)$ \\
\hline glifosato SAqC $\left({ }^{2}\right)$ & a $40,6 \mathrm{C}(42,5)$ & a $53,8 \mathrm{~B}(65,0)$ & a $56,3 \mathrm{~B}(68,7)$ & a $59,4 \mathrm{~B}(73,7)$ & a $73,2 \mathrm{~A}(91,2)$ \\
\hline glifosato GrDA $\left({ }^{3}\right)$ & b $26,7 \mathrm{D}(21,2)$ & b $37,5 \mathrm{C}(37,5)$ & b 45,7 C $(51,2)$ & a $61,1 \mathrm{~B}(76,2)$ & a $77,0 \mathrm{~A}(95,0)$ \\
\hline
\end{tabular}

dms para períodos sem chuva dentro de cada formulação $=9,42$

dms para formulações dentro de cada período sem chuva $=8,02$

* Dados transformados em arc sen $\sqrt{\%}$. * Os dados apresentados entre parênteses são os originais.

$\left({ }^{1}\right)$ ZAPP Qi.

$\left({ }^{2}\right)$ ROUNDUP CS.

$\left({ }^{3}\right)$ ROUNDUP WG.

Letras minúsculas do lado esquerdo e no sentido da colunas, comparam as formulações dentro de cada período; letras maiúsculas do lado direito e no sentido das linhas, comparam os períodos dentro de cada formulação.

Em algumas espécies, os melhores resultados de controle aparecem de forma mais evidente devido à maior suscetibilidade, absorção mais rápida e menos influenciada pelas chuvas que possam ocorrer em períodos curtos após a aplicação, além de maior rapidez e menor exigência de dosagens.

Entre as três principais plantas daninhas presentes na área experimental, o capim-marmelada foi a mais suscetível, enquanto para o capim-braquiária e o capim-colchão, o tempo de ação e consolidação dos sintomas finais foi maior. A maior velocidade de ação do glifosato potássico pode ser explicado pela presença na formulação de um sistema de adjuvantes devidamente balanceados. O sal de potássio possui alta solubilidade e higroscopicidade, o que lhe permite maior absorção em condições adversas de umidade.

$\mathrm{O}$ adjuvante não-iônico polialquilglicosídeo age principalmente na superfície da folha, e é completamente seletivo às células da epiderme, favorecendo a absorção e a difusão do ácido na planta, além de possuir alta higroscopicidade, o que favorece a absorção de água e reidratação após a secagem. 
O outro adjuvante utilizado é a amina etoxilada, com características catiônicas, responsáveis pela retenção e translocação do glifosato através da cutícula, aumento da permeabilidade dos tecidos, favorecendo a rápida absorção, além de atravessar a cutícula das folhas e melhorar as características da formulação quanto à viscosidade, o que facilita a dispersão da gota. Essas características propiciam a manutenção da gota de pulverização sobre a superfície da folha por mais tempo, favorecendo a movimentação do herbicida através da cutícula, sem causar danos às membranas das células das folhas, permitindo maior absorção e distribuição por todas as partes da planta (SYNGENTA, 2000).

\section{CONCLUSÃO}

1. Conclui-se que o controle da formulação glifosato potássico sobre as espécies avaliadas foi menos afetado pela chuva, necessitando de apenas quatro horas após sua aplicação para igualar-se ao intervalo superior a 48 horas sem chuva; as demais necessitaram de, no mínimo, seis horas.

\section{REFERÊNCIAS BIBLIOGRÁFICAS}

ANDERSON, M.D.; ARNOLD, W.E. Weed control in sunflowers (Helianthus annuus) with desmediphan and phenmediphan. Weed Science, Champaign, v.32, p.310-314, 1984.

BACHIEGA, A. L.; BASTOS, H.B.; OLIVEIRA, N. A. Efeito da chuva simulada sobre a eficácia de sulfosate e glifosate no controle de Brachiaria decumbens. In: CONGRESSO BRASILEIRO DA CIÊNCIA DAS PLANTAS DANINHAS, 22., 2000, Foz do Iguaçú. Resumos...Londrina: SBCPD, 2000. p.461.

BASTIANI, M.L.R.; SILVA, A.A.;FERREIRA, F.A.; CARDOSO, A.A. Influência de chuva simulada após aplicação de herbicida em pós-emergência, sobre o controle de plantas daninhas, em solo com dois níveis de umidade. Planta Daninha, Londrina, v.18, p.57-60, 2000.

BEHRENS, R.; ELAKKAD, M.A. Influence of rainfall on the phytotoxicity of foliarly applied 2,4-D. Weed Science, Champaign, v.29, p. 342 - 355, 1983.

BOERBOON, C.M.; WYSE, D.L. Influence of glyphosate concentration on glyphosate absorption and translocation in Canada thistle (Cirsium arvense). Weed Science, Champaign, v.36, p.291-5, 1988.
BOVEY, R.W.; MEYER, R.E.; WHISENANT, S.G. Effect of simulated rainfall on herbicide performance in huisache (Acacia farnesiana) and honey mesquite (Prosopis glandulosa). Weed Technology, Champaign, v.4, p.26-30, 1990.

CENTURION, J.F. Caracterização e classificação dos solos da Faculdade de Ciências Agrárias e Veterinárias de Jaboticabal. 1998. 84p. Tese (Livre Docência) - Faculdade de Ciências Agrárias e Veterinárias, Universidade Estadual Paulista, Jaboticabal.

DEUBER, R. Controle de plantas daninhas na cultura da soja. In: FUNDAÇÃO CARGIL. A soja no Brasil Central. 2.ed. Campinas, 1982. p. 367-392.

DEVINE, M.D.; BANDEEN, J.D.; MCKERSIE, B.D. Temperature effects on glyphosate absorption, translocation and distribution in quackgrass (Agropyron repens). Weed Science, Champaign, v.31, p.461-464, 1983.

DURIGAN, J.C. Efeitos de adjuvantes na aplicação e eficácia dos herbicidas. Jaboticabal: FUNEP, 1993. 42p. (Boletim Científico)

FENG, C.C.P.; SANDBRINK, J.J.; SAMMONS, D.R. Retention, uptake, and translocation of ${ }^{14} \mathrm{C}$-glyphosate from track-spray applications and correlation to rainfastness in velvetleaf (Abutilon theophrasti). Weed Technology, Champaign, v.14, p.127132,2000 .

HAMMERTON, J.L. Environmental factors and susceptibility to herbicides. Weeds, Champaign, v.15, p. 330-336, 1967.

KRUSE, N.D.; TREZZI, M.M.; VIDAL, R.A. Herbicidas inibidores da EPSPs: revisão de literatura. Revista Brasileira de Herbicidas, Brasília, v.1, n.2, p.139-146, 2000.

MAcISAAC, S.A.; PAUL, R.N.; DEVINE, M. A scanning electron microscope study of glyphosate deposits in relation to foliar uptake. Pesticide Science, Barking, v.31, p.53-64, 1991.

MAROCHI, A. I.; MIERLO, C.V.; GALLO, P. Avaliação do período ideal entre aplicação e ocorrência de chuva, para herbicidas de ação sistêmica, utilizados em dessecação para plantio direto. In: CONGRESSO BRASILEIRO DA CIÊNCIA DAS PLANTAS DANINHAS, 20., 1995, Florianópolis. Resumos... Florianópolis: SBCPD, 1995. p.318.

RODRIGUES, B.N.; ALMEIDA, F.S. Guia de herbicidas. 4.ed. Londrina: IAPAR, 1998. 648p.

SYNGENTA. Perfil técnico Zaap Qi. São Paulo: Syngenta Proteção de Cultivos Ltda. 2001. 13p. (Boletim Técnico)

TUCKER, T.A.; LANGELAND, K.A.; CORBIN, F.T. Absorption and translocation of ${ }^{14} \mathrm{C}$-Imazapyr and ${ }^{14} \mathrm{C}$-Glyphosate in alligatorweed Alternanthera philoxeroides. Weed Technology, Champaingn, v.8, p.32-6, 1994.

WALDECKER, M.A.; WYSE, D.L. Soil moisture effects on glyphosate absorption and translocation in common milkweed (Asclepias syriaca). Weed Science, Champaign, v.33, p.299-305, 1985. 